\title{
Project Management Tasks in Agile Projects: A Quantitative Study
}

\author{
Gloria J. Miller \\ Managing Consultant \\ maxmetrics \\ Heidelberg, Germany \\ https://orcid.org/0000-0003-2603-0980
}

\begin{abstract}
Recent studies have confirmed the efficacy of agile methodologies in project success. However, can projects skip several project management tasks and still deliver the expected results? How are traditional project managers engaged in agile projects? The results from this study quantify subjective and theoretical speculation on who performs the project management tasks in agile projects. Project managers are engaged in agile projects and the team, the product owner, and project sponsor are significantly involved in project management tasks. The agile coach is not a substitute for the project manager. The study identifies that agile and traditional methodologies should be updated to clarify team, product owner, and agile coach responsibilities.
\end{abstract}

\section{INTRODUCTION}

$\mathrm{W}$ HILE the adoption of agile project management methodologies is widespread [1], the project management tasks in agile projects are uncertain and the lack of clarity is causing confusion in practice $[2,3,4]$. Agile methodologies provide events, processes, and artifacts that should allow projects to be flexible to change and deliver results in an iterative, incremental fashion. Some of the most popular agile project management frameworks, such as scrum, extreme programming (XP), and lean/kanban processes do not explicitly include a project manager role or project management tasks. For example, scrum includes three roles: a scrum master, product owner, and the team.

Hobbs and Petit [4] identified 827 articles that compare or integrate agile project management with project management practices. However, not once did the research reference the effect of agile methodologies on the project manager role. Other agile research recognizes the confusion and conflict caused by the lack of recognition of the project manager in agile methodologies [5]. There is some speculation that the project manager is better suited to take over the product owner role [2] than the agile coach. While other research starts with the premise that there is an agile project manager who is a facilitator or coach $[6,7,8,9]$. Even the Agile Practice Guide issued by the Project Management Institute (PMI) in 2017 states that the "role of the Project Manager in an agile project is somewhat unknown" [10, p. 37]. In agile methodologies, some but not all of the typical project management responsibilities have been distributed to other roles [9].

The success rate for agile methodologies is on par with, if not better than, those managed under a traditional methodology [1]. Thus, if agile methodologies are followed rigorously and exclude a project manager, then maybe the project manager role and some project management tasks are obsolete. Shastri, Hoda and Amor [11] found that the project manager role does still exist in agile projects. However, the study left open the questions for why and what activities the project manager performs. "The implementation of agile methods can have a very significant impact on the role of the project manager, but a better understanding of the circumstances under which the project manager role changes and how it changes is needed" $[4, p$. 11]. Other studies have investigated agility in projects or the effects of specific practices on the success of projects applying agile methodologies $[1,12,13,14]$. Nevertheless, the topic of who performs what project management activities in agile projects remain unanswered. Specifically, how are traditional project managers engaged in agile projects? Who executes what project management tasks in projects applying agile methodologies?

First, we review the literature for understanding agile methodologies and the roles and tasks involved in the project work using agile and plan-driven methodologies. We map the responsibilities from an agile methodology to the project management knowledge areas and processes from the International Organization for Standardization (ISO) project management standard. Then, we define and conduct a survey to understand what roles perform which project management tasks. Finally, we quantitatively analyze the survey results and answer the research questions.

The results from this study quantify subjective and theoretical speculation on who performs the project management tasks in agile projects. The results contribute to the project management knowledge on agile methodologies by widening the perspective on the role of people, specifically the project manager, in agile projects. The next section reviews the literature and describes the research methodology, results, and discussions. The final sections of the study discuss the conclusions and implications. 


\section{LITERATURE REVIEW}

Traditional, waterfall or plan-driven methodologies follow a stage-gate or phased lifecycle. These methods have in common the creation of an upfront plan, where the time is limited with the limitation and termination conditions known from the beginning [15]. The methodologies and frameworks for traditional projects are codified in the project management standards and frameworks, such as "ISO 21500:2012, Guidance on Project Management" [16], APM Body of Knowledge 6th Edition [17], and A Guide to the Project Management Body of Knowledge (PMBOK guide) [18].

The Agile Manifesto is a set of four values and 13 principles that provide a framework for managing technology projects in a flexible way that responds to dynamic project situations $[1,19,20]$. There are at least 13 methodologies or frameworks that can be considered to follow the values and principles described in the Agile Manifesto. Each agile methodology has its own set of roles, rules, events, and practices; however, in general, they encourage iterative and incremental development life cycles, self-organizing teams, and evolutionary product development. Scrum, XP, lean, and Kanban are the most frequently referenced agile frameworks in surveys on agile adoption and in the project management literature [11].

The project manager is the authorized person who leads and manages project activities and is accountable for project completion [21]. The role is defined in ISO, APM, and PMI project management standards and frameworks. In addition, the standards describe knowledge areas that are expected of a project manager and processes that should be led or executed as part of managing a project. The project management literature agrees that the project manager has the sole responsibility for planning and managing projects [21]. The project manager should direct the performance of the planned project activities and manage the various technical, administrative and organizational interfaces within the project $[16,18]$. The project manager role is not explicit in the agile methodology. Noll, Razzak, Bass and Beecham [2] found that the scrum master, a coaching role in the scrum agile methodology, combines project management activities in practice. However, there was tension created since the scrum master should balance management activities with coaching the team. The inherit suggestion in studies about project managers in agile projects is that the leadership style or skills, knowledge, personal attributes and behavior of the project manager must be adapted [8, 9, 22, 23].

There are 39 processes in 10 subject areas that cover five process groups described for the project management role in the ISO project management standard $[16,20]$. The principles and values from the Agile Manifesto offer a framework on how people should work [20]. Consequently, the manifesto does not explicitly establish who should do the work. Binder, Aillaud and Schilli [20] correlated the 12 agile principles to the ISO processes to establish a hybrid model for managing agile projects. They identified gaps and practice modifications that would have to occur to effectively manage agile projects.

Project management success evaluates performance against the time, budget, and quality constraints of the project, also known in modern terminology as project efficiency [1]. Agile projects have been shown to have similar performance as traditional methodologies for project efficiency [1]. Nevertheless, the only success measure given for agile projects is working software [19].

The project management tasks in plan-driven methodologies are centralized to the project manager role. For agile methodologies, some of the project management responsibilities are inherent in the methods, while the project management activities or tasks or are not explicitly identified. Studies on project managers in agile projects have identified conflicts with other agile roles or assume project manager must adapt to manage agile projects.

\section{METHODOLOGY}

The research used a literature review to define the project boundary and project management authority, tasks, and roles in projects using plan-driven or agile methodologies. Peerreviewed journal publications from 2006 to 2018 were evaluated to identify project managers activities in agile projects. A web-based survey was used to collect data on the roles engaged in projects and the project management tasks they perform. A quantitative analysis method was used to explore the difference between the theoretical and practical applications of project management tasks.

The survey sample comprised 120 usable responses as follows: $33 \%$ of the respondents had a project manager role; $11 \%$ were program managers; $9 \%$ were from a project management office; $9 \%$ agile coaches or scrum masters; $8 \%$ product owners; $24 \%$ project team members from IT, business, software vendors, or others not in the selection list; $3 \%$ project sponsors, and less than $2 \%$ others. The organizations sponsoring the projects were spread throughout 20 different industries. The participants were balanced across geographic regions: Europe (25\%), Asia (19\%), Latin America, and the Caribbean (18\%,), North America (16\%), and Oceania (3\%). Most of the projects started in the last five years $(81 \%)$, lasted more than one year (56\%). and had less than 21 team members $(81 \%)$.

The SAS Studio (Release 3.6, basic edition) was used to perform the statistical analysis and produce the tables and figures. The responses were checked for scope, completeness, consistency, ambiguity, missing data, extreme responses, outliers, and leverage. No bias was found, and the data were reliable and valid. The number responses is comparable with other agile studies: [9] with 20 agile practitioners, and [11] with 97 and [6] with 32 survey respondents. Thus, the data were considered valid for further analysis. The descriptive statistics, mean ranking, Wilcoxon score, and correlation analysis were used to explore the characteristics, establish the validity and reliability, and explain the relationship between the variables. The descriptive statistics provide insight into the content and 
TABLE I

structure of the projects, the involvement of the different project roles, and the relationship between the involved roles and the methodology. The hypothesis testing uses regression analysis to explain the relationships between the roles that performed project management tasks and project efficiency.

\section{DATA ANALYSIS AND RESUlTS}

The analysis was performed for the four topic areas of project efficiency, methodology, roles, and tasks. Table I includes the mean comparison between methodology types; significant differences are based on the Kruskal Wallis being less than .05 for $95 \%$ confidence. Project budget, time, and quality performance were combined into a single project efficiency variable by taking the mean value of the variables. There is no significant difference between the composite project efficiency measure or the individual performance measures by methodology type. Different than some other research, the mixed and plan-driven methods have a higher mean than the agile methods [1].

Scrum and waterfall are the top methodologies at $22 \%$ and $20 \%$, respectively. From the agile methodologies, scrum combined with the scrum/XP is the most widely used at $24 \%$. This is consistent with other studies that found scrum to be the most popular agile methodology and agile methodologies are in wide-spread use $[1,11]$. The methodology types and methodologies were not significantly correlated with any of the individual performance measures or the project efficiency factor.

The project manager role was involved in $67 \%$ of the projects, including $58 \%$ of the agile projects, $82 \%$ of the mixed methodology projects, and $79 \%$ of the plan-driven projects. The agile coach role was included in $35 \%$ of all projects and the product owner role in $42 \%$ of all projects. There was no significant difference between methodologies for the other roles. The agile coach, product owner, and team combination - a full scrum team - was not present in all scrum-related projects. This implies that the scrum methodology is not being rigorously applied in practice. The project manager was more prominent in the plan-driven and mixed methodology, and the agile coach and product owner were more prominent in the agile methodologies. Otherwise, there was no significant difference in the roles between methodologies.

Project management tasks are performed in all types of methodologies with no significant difference. Overwhelmingly, the project manager is responsible for the project management tasks in all types of methodologies. This involvement is significant for managing the team and stakeholders, identifying risks, establishing the team, and controlling resources. On the other hand, the team is more often identified as being involved in assessing, treating, and controlling risks in plan-driven methodologies, while it is more often the product owner in agile methodologies. The product owner is strongly represented in managing stakeholders. The team and agile coach are not significantly engaged in this task. The project team is involved in
MEAN AND KRUSKAL-WALLIS TEST

\begin{tabular}{|c|c|c|c|c|c|}
\hline \multirow{2}{*}{ Theme } & \multirow{2}{*}{$\begin{array}{l}\text { Measurement } \\
\text { Item }\end{array}$} & \multicolumn{3}{|c|}{ Mean } & \multirow{2}{*}{$\begin{array}{c}\text { Kruskal } \\
\text { Wallis } \\
\text { p-Value }\end{array}$} \\
\hline & & Agile & $\begin{array}{c}\text { Plan- } \\
\text { driven }\end{array}$ & Mixed & \\
\hline \multirow{2}{*}{$\begin{array}{c}\text { Demo } \\
\text { graphics }\end{array}$} & Team Size & 3.57 & 3.06 & 3.41 & 0.26 \\
\hline & Duration & 2.42 & 2.29 & 2.48 & 0.82 \\
\hline \multirow{5}{*}{$\begin{array}{l}\text { Perform- } \\
\text { ance }\end{array}$} & Requirements & 5.01 & 5.06 & 5.31 & 0.60 \\
\hline & Project Eff & 4.43 & 4.39 & 4.89 & 0.34 \\
\hline & Budget & 4.33 & 4.35 & 4.97 & 0.48 \\
\hline & Time & 3.95 & 3.76 & 4.38 & 0.43 \\
\hline & Overall & 3.59 & 3.53 & 3.66 & 0.78 \\
\hline \multirow[t]{5}{*}{ Roles } & Team Role & 0.74 & 0.76 & 0.79 & 0.87 \\
\hline & Project Mgr. & 0.58 & 0.82 & 0.79 & 0.04 \\
\hline & Product Own & 0.53 & 0.41 & 0.14 & 0.00 \\
\hline & Sponsor & 0.38 & 0.53 & 0.38 & 0.50 \\
\hline & Agile Coach & 0.49 & 0.18 & 0.10 & 0.00 \\
\hline \multirow[t]{3}{*}{ Tasks } & Risk Mgt & 3.22 & 3.41 & 3.22 & 0.88 \\
\hline & $\begin{array}{l}\text { Procurement } \\
\text { Mgt }\end{array}$ & 2.65 & 2.5 & 3.17 & 0.34 \\
\hline & Resource Mgt & 2.65 & 2.55 & 2.30 & 0.52 \\
\hline
\end{tabular}

procurement in plan-driven methodologies and not at all involved in agile methodologies.

Fig. 1 combines the qualitative results from the literature review with the quantitative results and provides a consolidated view of project management responsibilities for agile projects. The rows represented the 39 ISO processes grouped into the 10 ISO subject areas, the columns represent the method or the project roles considered in the study, and the color represents the relative degree the processes are executed. For example, the integration subject area includes 6 processes: 2 map to 2 agile principles, 4 to 1 principle, and 1 does not map to any principles. The agile coach role maps to 3 processes for the subject area, the product owner to 2 , the team to 3 , the project manager to 6 , and the sponsor to 1 .

\section{DISCUSSION}

First, while agile project methodologies are popular; nevertheless, traditional methodologies continue to be in widespread use. No matter the methodology, the project management tasks as identified in the ISO standard for managing projects remain relevant. Project managers are engaged in agile projects to a larger degree than agile coaches or product owners. Project managers continue to perform management tasks and not only act as a "gatekeeper" as described by Taylor [3]. In this study, the sponsor and product owner undertook some management activities, while the agile coach did not. Thus, this partially supports the proposition by Noll, Razzak, Bass and Beecham [2] that assigning a former project manager to the product owner role rather than the scrum master role will result in a higher degree of project success. In practice, the project manager focuses on team management and risk identification 
tasks, while the product owners focus on the scope and stakeholder management. The product owner is responsible for the scope before the project start, during the project, and after the project is completed. A project manager is a transitory role and is not typically engaged in the market and withdrawal phases of a product lifecycle. Stated differently, the boundary for the product owner is the product features, while for the project manager, it is the project processes. Thus, the pairing of sponsor and product owner is a logical for the long-term product success and the sponsor and project manager for short-term project success.

From the study, it was clear that the agile coach has a much more limited set of tasks than the project manager. A sizable percentage of projects succeeded without an agile coach. The agile coach has two primary responsibility areas: developing the team and supporting all stakeholders to understand and apply the methods. In this regard, the management style suggested for an agile coach is that of a good leader, facilitator, or coach [22]. This corresponds with studies that argue project managers that can practice a facilitator leadership style could lead agile projects $[8,9,22$, 23]. However, the finding by Noll, Razzak, Bass and Beecham [2] that there is likely to be conflict within the project related to the delegation and management styles required by the different sets of responsibilities is a valid reason to separate the project manager and coaching roles. Furthermore, the results show that the agile coach was relevant to project efficiency but not to any of the project management tasks under investigation.

\section{CONCLUSIONS}

The tasks that would typically be carried out by a project manager continue to be practiced while they are not (explicitly) addressed by the agile methodologies. The team, product owner, and project sponsors are taking on the informal role on some project management tasks; the project manager continues to be engaged, albeit with an altered task distribution and leadership style.

The practical implication is that project sponsor should consider the project manager an essential role for all project types and not assign the project management activities to the sponsor or the product owner. The agile methodology authors should update their practices to identify the role the project team takes in assessing, treating, and controlling risks and in planning and managing suppliers. Furthermore, they should reflect the project management tasks that may be outside of the team operations but necessary for project sponsors or project managers to execute. Fig. 1 provides a guideline for mapping specific project roles to project management activities. Furthermore, since the rigorous application of the method is responsible for some typical project management activities, care should be taken to consider project governance when tailoring agile methods.

The agile coach is a key role that can improve the productivity of project operations. Thus, the role should be formalized into traditional methodologies as a role separate

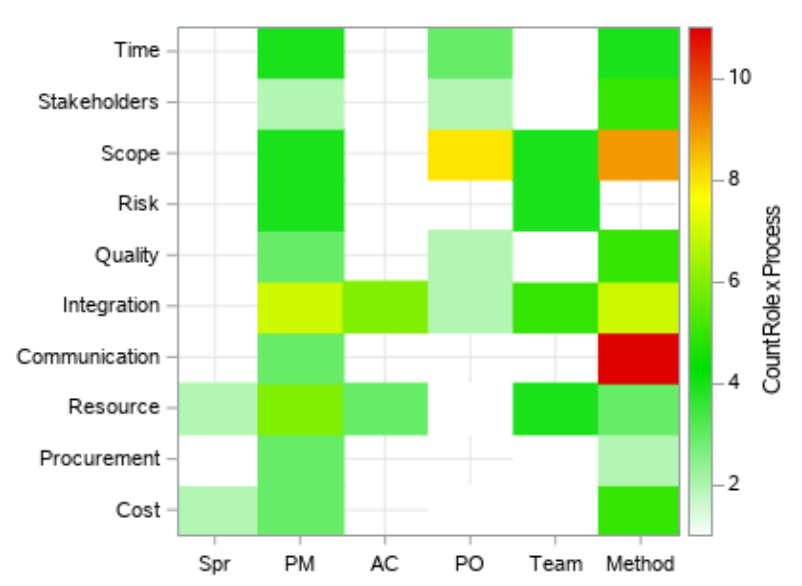

Fig 1. Heatmap of ISO process groups by scrum roles and agile methods based upon relative degree tasks, covered by the role after the analysis.

\section{Legend: Spr-Sponsor; PM-Project Manager; AC-Agile}

Coach; PO-Product Owner; Method-Agile Principles

from the project manager. Finally, researchers on agile methodologies should consider the participants within the projects in future studies. We determined that less than half the projects following a scrum methodology consist of all the scrum roles. Thus, the actual results from project studies may inappropriately contribute the successful outcomes to the methodology.

The results from this study quantify subjective and theoretical speculation on who performs the project management tasks in agile projects. The results of this study contribute to the project management knowledge on agile methodologies by widening the perspective on the role that people, specifically the project manager. Although agile methodologies are in widespread use, this information was missing in practice and under-researched in academia. Conversely, the research is limited in several ways. The results of this study are not generalizable beyond the methodologies studied in this research; specifically, software development projects have been the most active in applying agile methodologies. There were no measures to determine whether the project type skewed or biased the results. The research did not have financial or factual data to measure performance. Thus, it could only evaluate the perception of project performance as judged by the participants. Furthermore, the findings are limited due to the small sample size. Future research could focus on a qualitative study of the agile project organizations or seek to quantify the engagement of the separate roles.

\section{REFERENCES}

[1] P. Serrador and J. K. Pinto, "Does Agile work? - A quantitative analysis of agile project success," International Journal of Project Management, vol. 33, no. 5, pp. 1040-1051, July 2015, https://doi.org/ 10.1016/j.ijproman.2015.01.006. 
[2] J. Noll, M. A. Razzak, J. M. Bass, and S. Beecham, "A Study of the Scrum Master's Role," in Felderer M., Méndez Fernández D., Turhan B., Kalinowski M., Sarro F., Winkler D. (eds). Product-Focused Software Process Improvement. PROFES 2017, Springer, Cham, 2017.

[3] K. J. Taylor, "Adopting Agile software development: the project manager experience," Information Technology \& People, vol. 29, no. 4, pp. 670-687, 2016, https://doi.org/10.1108/ITP-02-2014-0031.

[4] B. Hobbs and Y. Petit, "Agile Methods on Large Projects in Large Organizations," Project Management Journal, vol. 48, no. 3, pp. 3-19, 2017, https://doi.org/10.1177/875697281704800301.

[5] K. Dikert, M. Paasivaara, and C. Lassenius, "Challenges and success factors for large-scale agile transformations: A systematic literature review," Journal of Systems and Software, vol. 119, no. pp. 87-108, Sept 2016, https://doi.org/10.1016/j.jss.2016.06.013.

[6] Z. Mansor, N. H. Arshad, S. Yahya, and R. Razali, "The competency of project managers in managing agile cost management," Advanced Science Letters, vol. 22, no. 8, pp. 1930-1934, 2016, https://doi.org/ 10.1166/asl.2016.7750.

[7] K. Conboy and L. Morgan, "Combining open innovation and agile approaches: implications for IS project managers," 2010.

[8] K. Sutling, Z. Mansor, S. Widyarto, S. Letchmunan, and N. H. Arshad, "Agile project manager behavior: The taxonomy," in 2014 8th. Malaysian Software Engineering Conference (MySEC), 2014, pp. 234239, https://doi.org/10.1109/MySec.2014.6986020.

[9] K. Sutling, Z. Mansor, S. Widyarto, S. Lecthmunan, and N. H. Arshad, "Understanding of project manager competency in agile software development project: The taxonomy," in Lecture Notes in Electrical Engineering. vol. 339, ed, 2015, pp. 859-868, https://doi.org/10.1007/ 978-3-662-46578-3_102.

[10] PMI, "Agile Practice Guide," ed: Project Management Institute, Inc., 2017.

[11] Y. Shastri, R. Hoda, and R. Amor, "Does the "Project Manager" Still Exist in Agile Software Development Projects?," in 2016 23rd AsiaPacific Software Engineering Conference (APSEC), 2016, pp. 57-64, https://doi.org/10.1109/APSEC.2016.019.
[12] K. M. Mayfield, "Project managers' experience and description of decision uncertainty associated with the agile software development methodology: A phenomenological study," 3427057 Ph.D., Capella University, Ann Arbor, 2010.

[13] J. Sheffield and J. Lemétayer, "Factors associated with the software development agility of successful projects," International Journal of Project Management, vol. 31, no. 3, pp. 459-472, March 2013, https:// doi.org/10.1016/j.ijproman.2012.09.011.

[14] V. Liubchenko, "A review of agile practices for project management," in 2016 XIth International Scientific and Technical Conference Computer Sciences and Information Technologies (CSIT), 2016, pp. 168-170, https://doi.org/10.1109/STC-CSIT.2016.7589897.

[15] R. A. Lundin and A. Söderholm, "A theory of temporary organization," Scandinavian Journal of Management, vol. 11, no. pp. 437-455, 1995, https://doi.org/10.1016/0956-5221(95)00036-U.

[16] ISO, "ISO 21500: 2012 Guidance on project management," in International Organization for Standardization, ed, 2012.

[17] APM, "APM body of Knowledge 6th Edition," ed: Association for Project Management, 2012.

[18] PMI, "A Guide to the Project Management Body of Knowledge (PMBOK Guide)," Sixth Edition ed. Newtown Square, PA: Project Management Institute, Inc., 2017.

[19] http://agilemanifesto.org/, "Manifesto for Agile Software Development," in Agile Manifesto, ed, 2001.

[20] J. Binder, L. I. V. Aillaud, and L. Schilli, "The Project Management Cocktail Model: An Approach for Balancing Agile and ISO 21500," Procedia - Social and Behavioral Sciences, vol. 119, no. pp. 182-191, March 2014, https://doi.org/10.1016/j.sbspro.2014.03.022.

[21] O. Zwikael and J. R. Meredith, "Who's who in the project zoo? The ten core project roles," International Journal of Operations \& Production Management, vol. 38, no. 2, pp. 474-492, 2018, https://doi.org/10 .1108/IJOPM-05-2017-0274.

[22] N. A. Bonner, "Predicting Leadership Success In Agile Environments: An Inquiring Systems Approach," Academy of Information and Management Sciences Journal, vol. 13, no. 2, pp. 83-103, Sep 2010.

[23] H. Yang, S. Huff, and D. Strode, "Leadership in software development: Comparing perceptions of agile and traditional project managers," AMCIS 2009 Proceedings, p. 184, 2009. 